\title{
Hollow $\mathrm{MO}_{x}-\mathrm{RuO}_{2}(\mathrm{M}=\mathrm{Co}, \mathrm{Cu}, \mathrm{Fe}, \mathrm{Ni}, \mathrm{CuNi})$ nanostructures as highly efficient electrodes for supercapacitors
}

\author{
Qiangqiang $\operatorname{Tan}^{1}$, Pengfei Wang ${ }^{1,2}$, Hui Liu ${ }^{1,3}$, Yuxing Xu ${ }^{1}$, Yunfa Chen ${ }^{1}$ and Jun Yang ${ }^{1,3^{*}}$
}

\begin{abstract}
Engineering the internal structure and chemical composition of nanomaterials in a cost-effective way has been challenging, especially for enhancing their performance for a given application. Herein, we report a general strategy to fabricate hollow nanostructures of ruthenium-based binary or ternary oxides via a galvanic replacement process together with a subsequent thermal treatment. In particular, the as-prepared $\mathrm{NiO}-\mathrm{RuO}_{2}$ hollow nanostructures loaded on carbon nanotubes $\left(\mathrm{hNiO}-\mathrm{RuO}_{2} / \mathrm{CNT}\right)$ with $\mathrm{RuO}_{2}$ mass ratio at $19.6 \%$ for a supercapacitor adopting the $\mathrm{KOH}$ electrolyte exhibit high specific capacitances of $740 \mathrm{~F} \mathrm{~g} \mathrm{~g}^{-1}$ at a constant current density of $1 \mathrm{~A} \mathrm{~g}^{-1}$ with good cycle stability. The specific capacitance for $\mathrm{hNiO}-\mathrm{RuO}_{2} / \mathrm{CNT}$ electrodes maintains 638.4 $\mathrm{F} \mathrm{g}^{-1}$ at a current density of $5 \mathrm{~A} \mathrm{~g}^{-1}$. This simple approach may shed some light on the way for making a wide range of metal oxides with tunable nanostructures and compositions for a variety of applications.
\end{abstract}

Keywords: ruthenium-based oxides, hollow nanostructures, galvanic replacement reaction, supercapacitor, specific capacitance

\section{INTRODUCTION}

A pesudocapacitor works based on the reversible Faradaic reactions (redox reactions) taking place on the electrode materials. However, chemical reactions are not $100 \%$ reversible even for the best combination of electrode materials and electrolyte. There are always some residual electrode materials that cannot participate in the reaction process, even after complete discharge. This is an unavoidable loss of active materials, which reduces the value of maximum specific capacitance with the increase of cycle numbers and affects the cycling stability of the pesudocapacitors. Despite the cyclic-stability issue, pesudocapacitors are still appealing due to their appropriate potential windows [1], higher energy density than that of conventional carbon materials, and better stability than conductive polymers [2-7].

Transition metal oxides are electrochemically active materials that facilitate redox reactions for charge build-up at the electrodes of pesudocapacitors [8-10]. Among various transition metal oxides as electrodes for supercapacitors, ruthenium dioxide $\left(\mathrm{RuO}_{2}\right)$ has been extensively studied because of its remarkably high theoretical specific capacitance, wide potential window, highly reversible redox reactions, good thermal stability, long cycle life, metallictype conductivity, and high rate capability [11-14].

Increasing the specific surface areas and alloying/incorporating with other inexpensive transition metals are two effective ways to improve the performance of $\mathrm{RuO}_{2}$ as electrode materials for supercapacitors. The former is capable for providing more active centers for the multiple redox reactions, which usually translates to the high specific capacitance, while the latter could not only significantly reduce the quantity of $\mathrm{RuO}_{2}$ required in the electrode layer, favorable for the practical utilization of valuable ruthenium metals, but also improve the overall capacitive behavior by making use of the possible synergistic effect between different metal oxides. A number of strategies, such as depositing $\mathrm{RuO}_{2}$ films on substrates with a rough surface [15-17], coating a thin $\mathrm{RuO}_{2}$ film on high-surface-area materials $[18,19]$, making nanometer-sized oxide electrodes [20,21], and decorating $\mathrm{RuO}_{2}$ particles with transition metal oxides [22-26], have been explored to maximize the surface area

\footnotetext{
${ }^{1}$ State Key Laboratory of Multiphase Complex Systems, Institute of Process Engineering, Chinese Academy of Sciences, Beijing 100190, China

${ }^{2}$ University of Chinese Academy of Sciences, Beijing 100049, China

${ }^{3}$ Center for Mesoscience, Institute of Process Engineering, Chinese Academy of Sciences, Beijing 100190, China

* Corresponding author (email: jyang@ipe.ac.cn)
} 
of $\mathrm{RuO}_{2}$, and reduce the $\mathrm{Ru}$ usage. Unfortunately, despite these intriguing achievements, a number of challenges remain to be addressed before the $\mathrm{RuO}_{2}$ can be commercially used as electrode materials for a supercapacitor. Typically, the surface area is usually difficult to tailor, and the strain developed in the $\mathrm{RuO}_{2}$ during the charge/discharge processes often causes the cracking of the electrode, leading to poor long-term stability $[27,28]$.

In this work, a general approach based on the combination of the galvanic replacement process with a subsequent thermal treatment was developed to generate carbon (C) or carbon nanotube (CNT)-supported hollow nanostructures of ruthenium-based binary or ternary oxides, labeled as $\mathrm{hMO}_{x}-\mathrm{RuO}_{2} / \mathrm{C}$ or $\mathrm{hMO}_{x}-\mathrm{RuO}_{2} / \mathrm{CNT}$, as highly efficient electrodes for supercapacitors. In this strategy, transition metal nanoparticles (TMNPs) including $\mathrm{Co}, \mathrm{Cu}, \mathrm{Fe}$, $\mathrm{Ni}$, or CuNi were first prepared in an organic solvent, and they were then used as seeds in a galvanic replacement process to react with $\mathrm{Ru}$ ion precursors for the preparation of binary or ternary M-Ru nanoparticles with hollow interiors (hM-RuNPs). Subsequently, the as-prepared binary or ternary hM-RuNPs were loaded on the C or CNT supports and heated at elevated temperature under air to convert the metals into metal oxides for the generation of $\mathrm{hMO}_{x}-\mathrm{RuO}_{2} / \mathrm{C}$ or $\mathrm{hMO}_{x}-\mathrm{RuO}_{2} / \mathrm{CNT}$ electrode materials. Advantageously, the hollow interiors not only provide a large electrochemical active surface area for fast and reversible Faradaic reactions, but also facilitate the proton transport in the $\mathrm{MO}_{x}-\mathrm{RuO}_{2}$ shell by shortening the diffusion distance, while the carbon or carbon nanotube supports serve as an excellent conductor for fast electron transfer, and is helpful to maintain the high surface area of binary or ternary metal oxide nanoparticles by preventing them from aggregation. As a result of this unique structure, the final $\mathrm{hMO}_{x}-\mathrm{RuO}_{2} / \mathrm{C}$ or $\mathrm{hMO}_{x}-\mathrm{RuO}_{2} / \mathrm{CNT}$ exhibits improved performance as electrode materials for supercapacitors using $\mathrm{KOH}$ as electrolyte. In addition, the hollow interior may benefit the long-term stability of the metal oxide nanoparticles by relieving the strain effect developed during the charge-discharge process.

\section{MATERIALS AND METHODS}

\section{General materials}

The chemical reagents, including ruthenium(III) chloride ( $\mathrm{RuCl}_{3}, \mathrm{Ru}$ content $\left.45-55 \%\right)$, cupper(II) acetylacetonate $\left(\mathrm{Cu}(\mathrm{acac})_{2}, 97.5 \%\right)$, nickel(II) acetylacetonate $\left(\mathrm{Ni}(\mathrm{acac})_{2}\right.$, 97.5\%), cobalt(II) acetylacetonate $\left(\mathrm{Co}(\mathrm{acac})_{2}, 97.5 \%\right)$ and iron(III) acetylacetonate $\left(\mathrm{Fe}(\mathrm{acac})_{3}, 97.5 \%\right)$ and oleylamine
(70\%, technical grade) from Sigma-Aldrich, potassium hydroxide (KOH, 99\%), ethanol (99.5\%), methanol (99\%), and toluene (99.5\%) from Beijing Chemical Works, stainless steel gauze (200 mesh woven from $0.05 \mathrm{~mm}$ diameter wire) and commercial ruthenium(IV) oxide hydrate $\left(\mathrm{RuO}_{2} \cdot x \mathrm{H}_{2} \mathrm{O}, 54 \% \mathrm{Ru}\right)$ with product number of 346088 from J\&K Scientific Ltd., Vulcan XC-72 carbon powders with a BET surface area of $250 \mathrm{~m}^{2} \mathrm{~g}^{-1}$ and an average particle size of 40-50 nm (XC-72C) from Cabot Corporation, carbon black with a BET surface area of $62 \mathrm{~m}^{2} \mathrm{~g}^{-1}$ (SUPER C65) from Swiss Timcal Ltd., and polytetrafluoroethylene (PTFE, 60 wt.\% aqueous dispersion) and multi-walled carbon nanotubes (CYL2-60) with a diameter of 40-60 $\mathrm{nm}$, a length of $1-2 \mu \mathrm{m}$ and a specific surface area of $100-150 \mathrm{~m}^{2} \mathrm{~g}^{-1}$ from Shanghai Aladdin Bio-Chem Technology Co., Ltd., were used as received. Deionized water was produced by a Milli-Q Ultrapure-water purification system. All glassware and Teflon-coated magnetic stir bars were cleaned with aqua regia, followed by copious washing with de-ionized water before drying in an oven.

\section{Synthesis of the transition metal (Co, Cu, Fe, Ni, CuNi) nanoparticles}

In a typical synthesis of a monometallic or bimetalic transition metal nanoparticles, $102.8 \mathrm{mg}$ of $\mathrm{Ni}(\mathrm{acac})_{2}, 104.7 \mathrm{mg}$ of $\mathrm{Cu}(\mathrm{acac})_{2}, 102.9 \mathrm{mg}$ of $\mathrm{Co}(\mathrm{acac})_{2}, 141.3 \mathrm{mg}$ of $\mathrm{Fe}(\mathrm{acac})_{3}$, or a mixture consisting of $51.4 \mathrm{mg}$ of $\mathrm{Ni}(\mathrm{acac})_{2}$ and $52.4 \mathrm{mg}$ of $\mathrm{Cu}(\mathrm{acac})_{2}$ was added to $20 \mathrm{~mL}$ of oleylamine in a threenecked flask fitted with a condenser and a stir bar. The solution was heated and kept at target temperature $\left(160^{\circ} \mathrm{C}\right.$ for $\mathrm{Ni}$, Co and $\mathrm{Fe}, 190^{\circ} \mathrm{C}$ for $\mathrm{Cu}$, and $190^{\circ} \mathrm{C}$ for $\mathrm{CuNi}$ ) under flowing $\mathrm{N}_{2}$ for $2 \mathrm{~h}$ for the reduction of transition metal ions by oleylamine. After reaction, the monometallic or bimetallic transition metal nanoparticles were purified by precipitation with methanol, centrifugation, washing with methanol, and re-dispersed in $20 \mathrm{~mL}$ of toluene.

\section{Synthesis of the hollow structured M-Ru nanoparticles}

Typically, $104.7 \mathrm{mg}$ of $\mathrm{Ni}(\mathrm{acac})_{2}, 102.8 \mathrm{mg}$ of $\mathrm{Cu}(\mathrm{acac})_{2}$, $102.9 \mathrm{mg}$ of $\mathrm{Co}(\mathrm{acac})_{2}, 141.3 \mathrm{mg}$ of $\mathrm{Fe}(\mathrm{acac})_{3}$, or a mixture consisting of $51.4 \mathrm{mg}$ of $\mathrm{Ni}(\mathrm{acac})_{2}$ and $52.4 \mathrm{mg}$ of $\mathrm{Cu}(\mathrm{acac})_{2}$ was added to $20 \mathrm{~mL}$ of oleylamine in a three-necked flask fitted with a condenser and a stir bar. The solution was heated and kept at target temperature $\left(160^{\circ} \mathrm{C}\right.$ for $\mathrm{Ni}$, Co and $\mathrm{Fe}, 190^{\circ} \mathrm{C}$ for $\mathrm{Cu}$, and $190^{\circ} \mathrm{C}$ for $\mathrm{CuNi}$ ) under flowing $\mathrm{N}_{2}$ for $2 \mathrm{~h}$ for the reduction of transition metal ions. Then $40.7 \mathrm{mg}$ of $\mathrm{RuCl}_{3}$ was added swiftly, followed by increasing the temperature to $240^{\circ} \mathrm{C}$ and keeping at the temperature for $2 \mathrm{~h}$ for 
the completion of the replacement reaction between transition metal nanoparticles and Ru ion precursors. After reaction, the as-obtained binary or ternary $\mathrm{M}-\mathrm{Ru}$ nanoparticles with hollow interiors, labeled as hM-RuNPs, were purified by precipitation with methanol, centrifugation, washing with methanol, and re-dispersed in $20 \mathrm{~mL}$ of toluene.

\section{Loading the hM-RuNPs on carbon or carbon nanotube supports}

For the loading of the hM-RuNPs on the Vulcan XC-72 carbon or CYL2-60 carbon nanotube supports, $30 \mathrm{mg}$ of carbon powder or CNT was added to the toluene solution of hM-RuNPs. After stirring the mixture for $24 \mathrm{~h}$, the hM-RuNPs supported on C or CNT labeled as hM-Ru/C or $\mathrm{hM}-\mathrm{Ru} / \mathrm{CNT}$ were collected by centrifugation, washed thrice with ethanol, and then dried at room temperature in vacuum.

\section{Synthesis of the $\mathrm{hMO}_{x}-\mathrm{RuO}_{2} / \mathrm{C}$ or $\mathrm{hMO}_{x}-\mathrm{RuO}_{2} / \mathrm{CNT}$}

The $\mathrm{hM}-\mathrm{Ru} / \mathrm{C}$ and $\mathrm{hM}-\mathrm{Ru} / \mathrm{CNT}$ as-prepared above were heated at $350^{\circ} \mathrm{C}$ in air for $6 \mathrm{~h}$ to convert the transition metals and $\mathrm{Ru}$ into their oxide states $\left(\mathrm{MO}_{x}\right.$ and $\mathrm{RuO}_{2}$ ) for the generation of the final $\mathrm{hMO}_{x}-\mathrm{RuO}_{2} / \mathrm{C}$ or $\mathrm{hMO}_{x}-\mathrm{RuO}_{2} / \mathrm{CNT}$ electrode materials.

\section{Particle characterizations}

Transmission electron microscopy (TEM), high-resolution TEM (HRTEM) and scanning TEM (STEM) were performed on the JEOL JEM-2100 and FEI Tecnai G ${ }^{2}$ F20 electron microscope operating at $200 \mathrm{kV}$ with supplied software for automated electron tomography. For the TEM measurements, a drop of the particle solution was dispensed onto a 3-mm carbon-coated copper grid (or molybdenum grid for the samples containing copper). Excessive solution was removed by an absorbent paper, and the sample was dried under vacuum at room temperature. An energy dispersive X-ray spectroscopy (EDX) analyzer attached to the TEM was used to determine the element distributions in the hollow structured nanoparticles. The mean particle size, the average thickness of the shells, and the standard deviations were calculated from a few randomly chosen areas in the TEM image containing approximately 100 nanoparticles each. The metal contents were measured using inductively coupled plasma atomic emission spectrophotometry (ICP-AES, Optima 5300DV, Perkin Elmer). X-ray photoelectron spectroscopy (XPS) was conducted on a VG ESCALAB MKII spectrometer. Powder X-ray diffraction (XRD) patterns were recorded on a Rigaku D/Max-3B diffractometer, using $\mathrm{Cu}$ Ka radiation $(\lambda=1.54056 \AA$ ) . Samples for XPS and XRD analyses were concentrated from the toluene solution of nanoparticles to $0.5 \mathrm{~mL}$ using flowing $\mathrm{N}_{2}$. Ten milliliters of methanol was then added to precipitate the nanoparticles, which were recovered by centrifugation, washed with methanol, and then dried at room temperature in vacuum.

\section{Fabrication of the electrode and the electrochemical measurements}

The working electrodes were fabricated by mixing the as-prepared hollow oxides $\left(\mathrm{hCoO}-\mathrm{RuO}_{2} / \mathrm{C}\right.$, hCoO- $\mathrm{RuO}_{2} / \mathrm{CNT}, \quad \mathrm{hCuO}-\mathrm{RuO}_{2} / \mathrm{C}, \mathrm{hCuO}-\mathrm{RuO}_{2} / \mathrm{CNT}$, $\mathrm{hFe}_{2} \mathrm{O}_{3}-\mathrm{RuO}_{2} / \mathrm{C}, \quad \mathrm{hFe}_{2} \mathrm{O}_{3}-\mathrm{RuO}_{2} / \mathrm{CNT}, \mathrm{hNiO}-\mathrm{RuO}_{2} / \mathrm{C}$, $\mathrm{hNiO}-\mathrm{RuO}_{2} / \mathrm{CNT}, \quad \mathrm{hCuNiO}-\mathrm{RuO}_{2} / \mathrm{C}$, or hCuNiO$\mathrm{RuO}_{2} / \mathrm{CNT}$ ) or commercial $\mathrm{RuO}_{2}$, carbon black, and polytetrafluoroethylene (PTFE) with a mass ratio of 85/10/5. The mixture was dispersed in small amount of ethanol for the formation of paste, and was then pressed into slices and dried at $100^{\circ} \mathrm{C}$ for $10 \mathrm{~h}$ in vacuum. Subsequently, the slices were coated onto the stainless steel gauzes under the pressure of $10 \mathrm{MPa}$ to obtain the electrode. The mass of as-prepared $\mathrm{hMO}_{x}-\mathrm{RuO}_{2} / \mathrm{C}$ or $\mathrm{hMO}_{x}-\mathrm{RuO}_{2} / \mathrm{CNT}$ coated on the stainless steel gauze was $4.0 \mathrm{mg}$.

All of the electrochemical measurements were carried out using a two electrode setup: the stainless steel gauzes that coated with $\mathrm{hMO}_{x}-\mathrm{RuO}_{2} / \mathrm{C}$ or $\mathrm{hMO}_{x}-\mathrm{RuO}_{2} / \mathrm{CNT}$ was used as the working electrode, and the coin-cells $(20 \mathrm{~mm}$ in diameter and $1.6 \mathrm{~mm}$ in thickness) fabricated with polypropylene membrane (purchased from NKK, $45 \mu \mathrm{m}$ in thickness) were used as the separator. The cells were aged for $24 \mathrm{~h}$ before measurement. The measurements were performed in $6 \mathrm{~mol} \mathrm{~L}^{-1}$ aqueous $\mathrm{KOH}$ electrolyte at room temperature. Cyclic voltammetry (CV), galvanostatic charge-discharge test, and electrochemical impedance spectroscopy (EIS) measurements were obtained using a CHI650 electrochemical workstation. CV tests were done between 0 and $1.2 \mathrm{~V}$ at the scan rates of $20,50,100$, and $200 \mathrm{mV} \mathrm{s}^{-1}$. Charge-discharge cycling tests at a constant current mode between 0 and $1 \mathrm{~V}$ and the rate capability at current densities of $0.5,1,2,5 \mathrm{~A} \mathrm{~g}^{-1}$ were performed on a computer controlled Land battery tester. EIS measurements were conducted over the frequency range from 100 $\mathrm{kHz}$ to $10 \mathrm{mHz}$. The specific capacitance of the electrode can be calculated using the following equation:

$$
C=I t / \Delta V m,
$$

where $C$ is the specific capacitance $\left(\mathrm{F} \mathrm{g}^{-1}\right), I$ is the response current density $\left(\mathrm{A} \mathrm{g}^{-1}\right), t$ is the discharge time (s), $\Delta V$ is the potential $(\mathrm{V})$, and $m$ is the mass of the electroactive 
materials in the electrodes (g).

\section{RESULTS AND DISCUSSION}

Fig. 1 schematically shows the overall strategy for the formation of $\mathrm{hMO}_{x}-\mathrm{RuO}_{2} / \mathrm{C}$ or $\mathrm{hMO}_{x}-\mathrm{RuO}_{2} / \mathrm{CNT}$ electrode materials. Monometallic or bimetallic TMNPs were firstly synthesized by reducing their single or mixed acetylacetonate precursors in oleylamine, which serves as solvent, capping surfactant and reducing agent [29-31]. The TMNPs thus obtained were then used as seeds for the subsequent replacement reaction with ruthenium $(\mathrm{Ru})$ ions. The TEM and HRTEM images of the TMNPs as-prepared in oleylamine are shown in Fig. S1 (Supplementary information (SI)). As displayed, these TMNPs are quasi-spherical, nearly dispersed, and have an average diameter of ca. $20.8 \mathrm{~nm}$ for Co, $29.8 \mathrm{~nm}$ for $\mathrm{Cu}, 16.2 \mathrm{~nm}$ for Fe, $31.6 \mathrm{~nm}$ for $\mathrm{Ni}$, and $40.6 \mathrm{~nm}$ for $\mathrm{CuNi}$, respectively. The successful preparation of the TMNPs was confirmed by heir XPS analyses (Fig. S2). The 2p spectra of all the TMNPs can be de-convoluted into two pairs of doublets. The more intense doublet (at 778.5 and 794.6 eV for Co, 933.1 and 952.8 $\mathrm{eV}$ for $\mathrm{Cu}, 707.0$ and $720.1 \mathrm{eV}$ for $\mathrm{Fe}, 852.8$ and $870.1 \mathrm{eV}$ for $\mathrm{Ni}, 932.0$ and $951.8 \mathrm{eV}$ for $\mathrm{Cu}$ in bimetallic $\mathrm{CuNi}$, and 853.4 and $870.6 \mathrm{eV}$ for $\mathrm{Ni}$ in bimetallic $\mathrm{CuNi}$, respectively) corresponds to the transition metals at zero valent state, while the second and weaker doublet, with binding energies higher than those of zero valent transition metals could be assigned to $\mathrm{Co}, \mathrm{Cu}, \mathrm{Fe}$, and $\mathrm{Ni}$ at oxidized state, e.g., $\mathrm{CoO}$, $\mathrm{CuO}, \mathrm{Fe}_{2} \mathrm{O}_{3}$, and $\mathrm{NiO}[32,33]$. In addition, for $\mathrm{Co}, \mathrm{Cu}$ and $\mathrm{Ni}$, the satellite peaks in their XPS spectra are also observed $[34,35]$.



Figure 1 Schematic illustration showing the formation of $\mathrm{hMO}_{x}-\mathrm{RuO}_{2} / \mathrm{C}$ or $\mathrm{hMO}_{x}-\mathrm{RuO}_{2} / \mathrm{CNT}$ electrode materials: (a) hM-RuNPs were firstly prepared via galvanic replacement between TMNPs and Ru ion precursors, (b) the as-prepared hM-RuNPs were loaded on carbon or carbon nanotube supports, and then (c) the hM-RuNPs were converted into $\mathrm{hMO}_{x^{-}}$ $\mathrm{RuO}_{2}$ particles on the carbon or carbon nanotube supports via thermal treatment.
As displayed in Fig. 1, in the strategy developed in this work, the preparation of binary or ternary hM-RuNPs is an important step preceding the fabrication of $\mathrm{hMO}_{x}-\mathrm{RuO}_{2} / \mathrm{C}$ or $\mathrm{hMO}_{x}-\mathrm{RuO}_{2} / \mathrm{CNT}$ electrode materials. The binary or ternary hM-RuNPs were synthesized using a seed-mediated growth method at elevated temperature. The replacement reaction between TMNPs and the Ru ion precursors in oleylamine can be described as $3 \mathrm{M}+x \mathrm{Ru}^{3+} \rightarrow x \mathrm{Ru}+$ $3 \mathrm{M}^{x+}$, where $\mathrm{M}$ means transition metals at zero valent state. Pure TMNPs are transformed into alloy shells composed of corresponding transition metal and $\mathrm{Ru}$ by galvanic replacement [36-38]. Actually, the real process occurred in the solution is more complicated. In addition to the replacement reaction between TMNPs and Ru precursors, it also involves the oleylamine reduction of transition metal ions generated from galvanic replacement, the reduction of $\mathrm{Ru}$ ions added to the solution, and perhaps the alloying between $\mathrm{Ru}$ and transition metal atoms. Overall, these closely knitted reactions collectively facilitate the formation of binary or ternary nanoshells consisting of $\mathrm{Ru}$ and corresponding transition metals.

The typical TEM and HRTEM images of the as-prepared hM-RuNPs are shown in Figs $2 \mathrm{a}_{1}-\mathrm{e}_{1}$ and $2 \mathrm{a}_{2}-\mathrm{e}_{2}$, respectively, in which the hollow interiors could be clearly discerned by the strong brightness contrast between central and surface regions. These binary and ternary hM-RuNPs have an average size of ca. $14.2 \mathrm{~nm}$ for hCo-RuNPs, 18.6 $\mathrm{nm}$ for hCu-RuNPs, $16.4 \mathrm{~nm}$ for hFe-RuNPs, $23.8 \mathrm{~nm}$ for hNi-RuNPs, and $34.4 \mathrm{~nm}$ for hCuNi-RuNPs, respectively. Except for the hFe-RuNPs, which remain same size as their Fe seeds, the as-prepared hM-RuNPs are smaller in diameter in comparison with their corresponding transition metal seed particles. The alloy nature in the shells of the binary and ternary hM-RuNPs could be confirmed by the distributions of transition metals and $\mathrm{Ru}$ in the binary and ternary hM-RuNPs, which were analyzed by EDX under the high-angle annular dark-field scanning TEM (HAADF-STEM) mode. As demonstrated by Figs $2 \mathrm{a}_{3}-\mathrm{a}_{6}$ for hCo-RuNPs, $2 \mathrm{~b}_{3}-\mathrm{b}_{6}$ for $\mathrm{hCu}$-RuNPs, $2 \mathrm{c}_{3}-\mathrm{c}_{6}$ for hFe-RuNPs, $2 \mathrm{~d}_{3}-\mathrm{d}_{6}$ for hNi-RuNPs, and $2 \mathrm{e}_{3}-\mathrm{e}_{7}$ for hCuNi-RuNPs, respectively, the nanoscale elemental mappings reveal that the corresponding transition metals and $\mathrm{Ru}$ are distributed uniformly in the shell regions. The elemental mapping assays are well in accord with the line scanning analyses of a number of hM-RuNPs in the HAADF-STEM mode (Figs $2 \mathrm{a}_{7}$ for hCo-RuNPs, $2 \mathrm{~b}_{7}$ for hCu-RuNPs, $2 \mathrm{c}_{7}$ for hFe-RuNPs, $2 \mathrm{~d}_{7}$ for hNi-RuNPs, and $2 \mathrm{e}_{8}$ for hCuNi-RuNPs, respectively), which also show the uniform distribution of the corresponding transition 
metals and Ru throughout the shells of hM-RuNPs. The average thickness of the shells and their standard deviations, which are calculated directly from the TEM images, are $1.6 \mathrm{~nm}$ and $0.31 \mathrm{~nm}$ for hCo-RuNPs, $1.3 \mathrm{~nm}$ and $0.22 \mathrm{~nm}$ for hCu-RuNPs, $1.5 \mathrm{~nm}$ and $0.41 \mathrm{~nm}$ for hFe-RuNPs, 2.2 $\mathrm{nm}$ and $0.55 \mathrm{~nm}$ for hNi-RuNPs, and $3.4 \mathrm{~nm}$ and $0.98 \mathrm{~nm}$ for hCuNi-RuNPs, respectively. Furthermore, the HRTEM images (Figs $2 \mathrm{a}_{2}-\mathrm{e}_{2}$ ) not only indicate the presence of
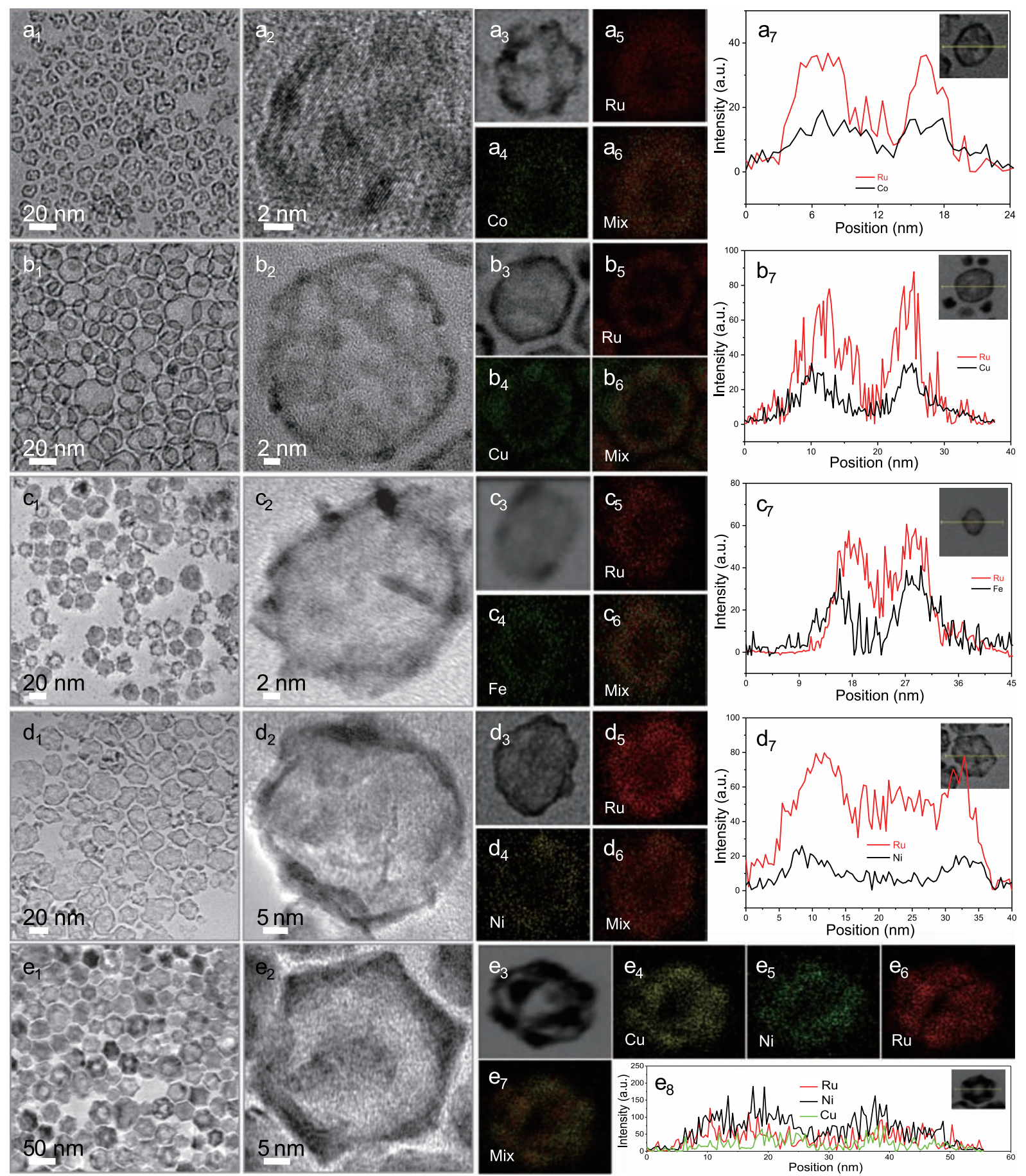

Figure 2 TEM images $\left(a_{1}-e_{1}\right)$, HRTEM images $\left(a_{2}-e_{2}\right)$, elemental mapping analyses $\left(a_{3}-a_{6}, b_{3}-b_{6}, c_{3}-c_{6}, d_{3}-d_{6}, e_{3}-e_{7}\right)$, and element profiles $\left(a_{7}-d_{7}\right.$, $\left.e_{8}\right)$ of binary Co- $\mathrm{Ru}\left(\mathrm{a}_{1}-\mathrm{a}_{7}\right), \mathrm{Cu}-\mathrm{Ru}\left(\mathrm{b}_{1}-\mathrm{b}_{7}\right), \mathrm{Fe}-\mathrm{Ru}\left(\mathrm{c}_{1}-\mathrm{c}_{7}\right), \mathrm{Ni}-\mathrm{Ru}\left(\mathrm{d}_{1}-\mathrm{d}_{7}\right)$, and ternary CuNi-Ru hollow structured nanoparticles $\left(\mathrm{e}_{1}-\mathrm{e}_{8}\right)$ synthesized in oleylamine via galvanic replacement between TMNPs and Ru ion precursors. 
hollow interiors in the hM-RuNPs, but also reveal the additional structural details. The discontinuous feature of the alloy shell could be clearly identified. The formation of the discontinuous alloy shells is important, as it permits the access of the inner surfaces for the occurrence of multiple redox reactions.
After aging the mixture of hM-RuNPs in toluene and carbon or carbon nanotube for $24 \mathrm{~h}$ at room temperature, the nanoparticles could be efficiently loaded on the carbon or carbon nanotube supports, leaving behind a clear toluene phase. The representative TEM images (Figs $3 \mathrm{a}, \mathrm{e}, \mathrm{i}, \mathrm{m}$, and $\mathrm{q}$ for carbon- and Figs $3 \mathrm{c}, \mathrm{g}, \mathrm{k}, \mathrm{o}$, and $\mathrm{s}$ for carbon nanotube-
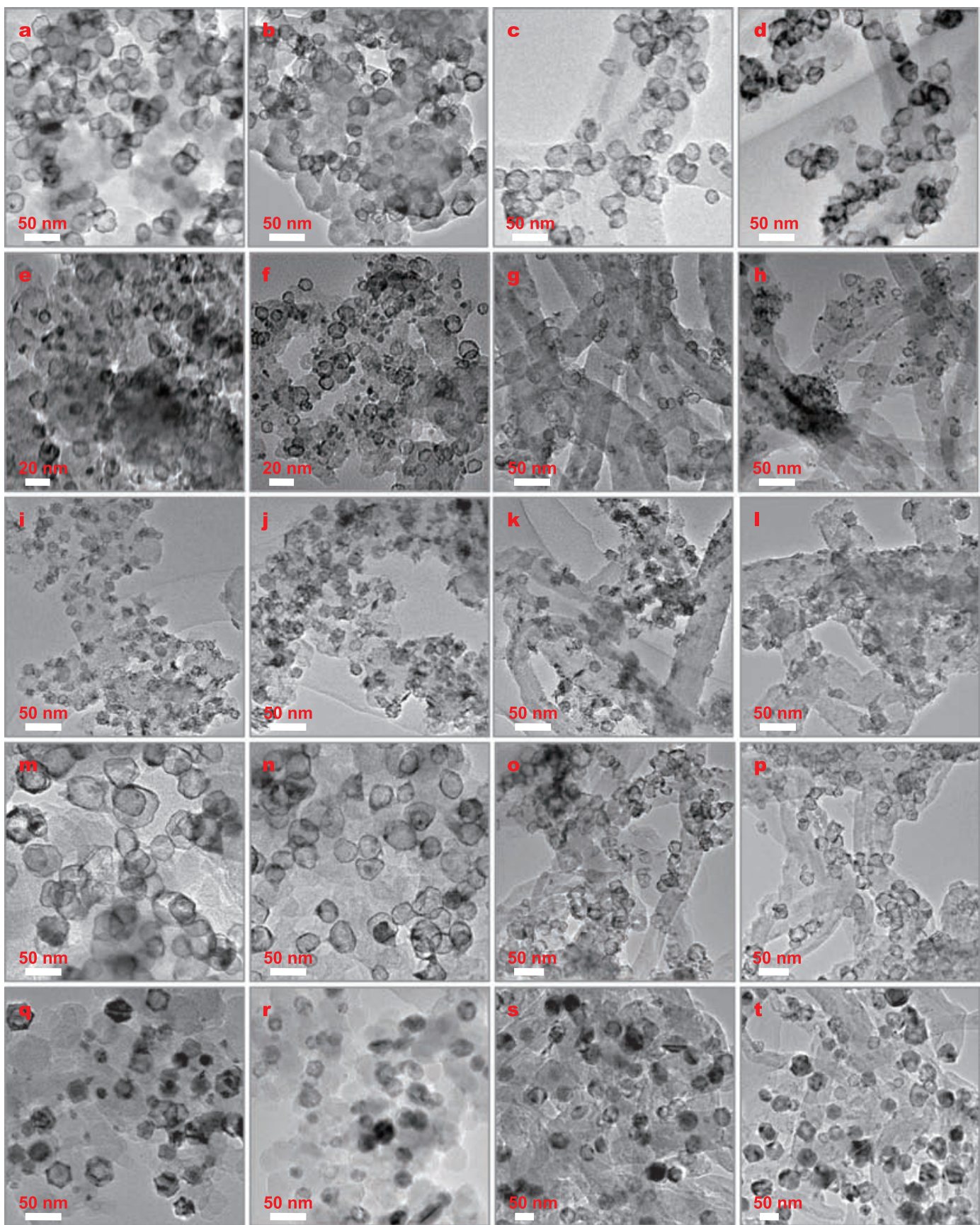

Figure 3 TEM images of the as-prepared hCo-Ru (a, c), hCoO- $\mathrm{RuO}_{2}(\mathrm{~b}, \mathrm{~d}), \mathrm{hCu}-\mathrm{Ru}(\mathrm{e}, \mathrm{g}), \mathrm{hCuO}-\mathrm{RuO}_{2}(\mathrm{f}, \mathrm{h}), \mathrm{hFe}-\mathrm{Ru}(\mathrm{i}, \mathrm{k}), \mathrm{hFe}_{2} \mathrm{O}_{3}-\mathrm{RuO}_{2}$ (j, l), hNi-Ru $(\mathrm{m}, \mathrm{o}), \mathrm{hNiO}-\mathrm{RuO}_{2}(\mathrm{n}, \mathrm{p}), \mathrm{hCuNi}-\mathrm{Ru}(\mathrm{q}, \mathrm{s})$, and $\mathrm{hCu}_{0.6} \mathrm{Ni}_{0.4} \mathrm{O}-\mathrm{RuO}_{2}(\mathrm{r}, \mathrm{t})$ supported on carbon $(\mathrm{a}, \mathrm{b}, \mathrm{e}, \mathrm{f}, \mathrm{i}, \mathrm{j}, \mathrm{m}, \mathrm{n}, \mathrm{q}, \mathrm{r})$ and carbon nanotubes $(\mathrm{c}, \mathrm{d}, \mathrm{g}, \mathrm{h}$, $\mathrm{k}, \mathrm{l}, \mathrm{o}, \mathrm{p}, \mathrm{s}, \mathrm{t})$. 
supported hCo- $\mathrm{Ru}, \mathrm{hCu}-\mathrm{Ru}, \mathrm{hFe}-\mathrm{Ru}, \mathrm{hNi}-\mathrm{Ru}$, and hCuNi-Ru, respectively) show that the binary and ternary hM-RuNPs are dispersed very well on the carbon or carbon nanotube supports. Subsequently, the hM-Ru/C and $\mathrm{hM}-\mathrm{Ru} / \mathrm{CNT}$ were subjected to calcination at $350^{\circ} \mathrm{C}$ in air for $6 \mathrm{~h}$ to convert the transition metals and $\mathrm{Ru}$ in the nanoshells into their oxidized states for the generation of final $\mathrm{hMO}_{x}-\mathrm{RuO}_{2} / \mathrm{C}$ or $\mathrm{hMO}_{x}-\mathrm{RuO}_{2} / \mathrm{CNT}$ electrode materials.

We employed carbon-supported hM-RuNPs as the typical examples to carry out the XPS examinations, which were used to determine the chemical states of the transition metals and Ru before and after calcination. The XPS results of $\mathrm{Ru}$ in hM-RuNPs before and after calcination are shown in Fig. 4. Because the $\mathrm{Ru} 3 \mathrm{~d}_{3 / 2}$ peak overlaps with the $C$ 1s peak in XPS spectra, preventing an unambiguous analysis of the nanoparticle surface, the Ru 3p XPS peak is used instead. As shown in Figs 4a, c, e, g, and i for the XPS spectra of the Ru in hCo-Ru, hCu-Ru, hFe-Ru, hNi-Ru, and hCuNi-Ru before calcination, the doublets at 461.9-462.5
$\mathrm{eV}$ and $484.2-484.8 \mathrm{eV}$ are signatures of $\mathrm{Ru}$ metal in the zero valent state [32]. However, after calcination in air, the doublets at 463.6-463.9 eV and 486.1-486.4 eV for the $\mathrm{Ru}$ in hM-RuNPs, which reflect the $\mathrm{Ru}$ at oxidized state, e.g., $\mathrm{RuO}_{2}$ [32,39-41], can fit for the XPS spectra very well (Figs $4 \mathrm{~b}, \mathrm{~d}, \mathrm{f}, \mathrm{h}$, and $\mathrm{j}$ for the XPS spectra of the $\mathrm{Ru}$ in hCo-Ru, hCu-Ru, hFe-Ru, hNi-Ru, and hCuNi-Ru after calcination), indicating that the complete conversion from $\mathrm{Ru}$ to $\mathrm{RuO}_{2}$ has been achieved upon the thermal treatment of hM-RuNPs in air at elevated temperature. The XPS spectra of the corresponding transition metals in hM-RuNPs before and after calcination are shown in Fig. S3. As displayed, all transition metals have been partially oxidized before calcination because they are susceptible to oxidation (Figs S3a, c, e, g, i, and 1 for Co in hCo-Ru, Cu in $\mathrm{hCu}-\mathrm{Ru}, \mathrm{Fe}$ in hFe-Ru, Ni in hNi-Ru, $\mathrm{Cu}$ in hCuNi-Ru, and $\mathrm{Ni}$ in hCuNi-Ru, respectively). However, after calcination, the XPS peaks associated with the zero valent state disappeared, as exhibited in Figs S3b, d, f, h, j, and $m$ for Co in $\mathrm{hCo}-\mathrm{Ru}, \mathrm{Cu}$ in hCu-Ru, Fe in hFe-Ru, Ni in hNi-Ru, Cu in
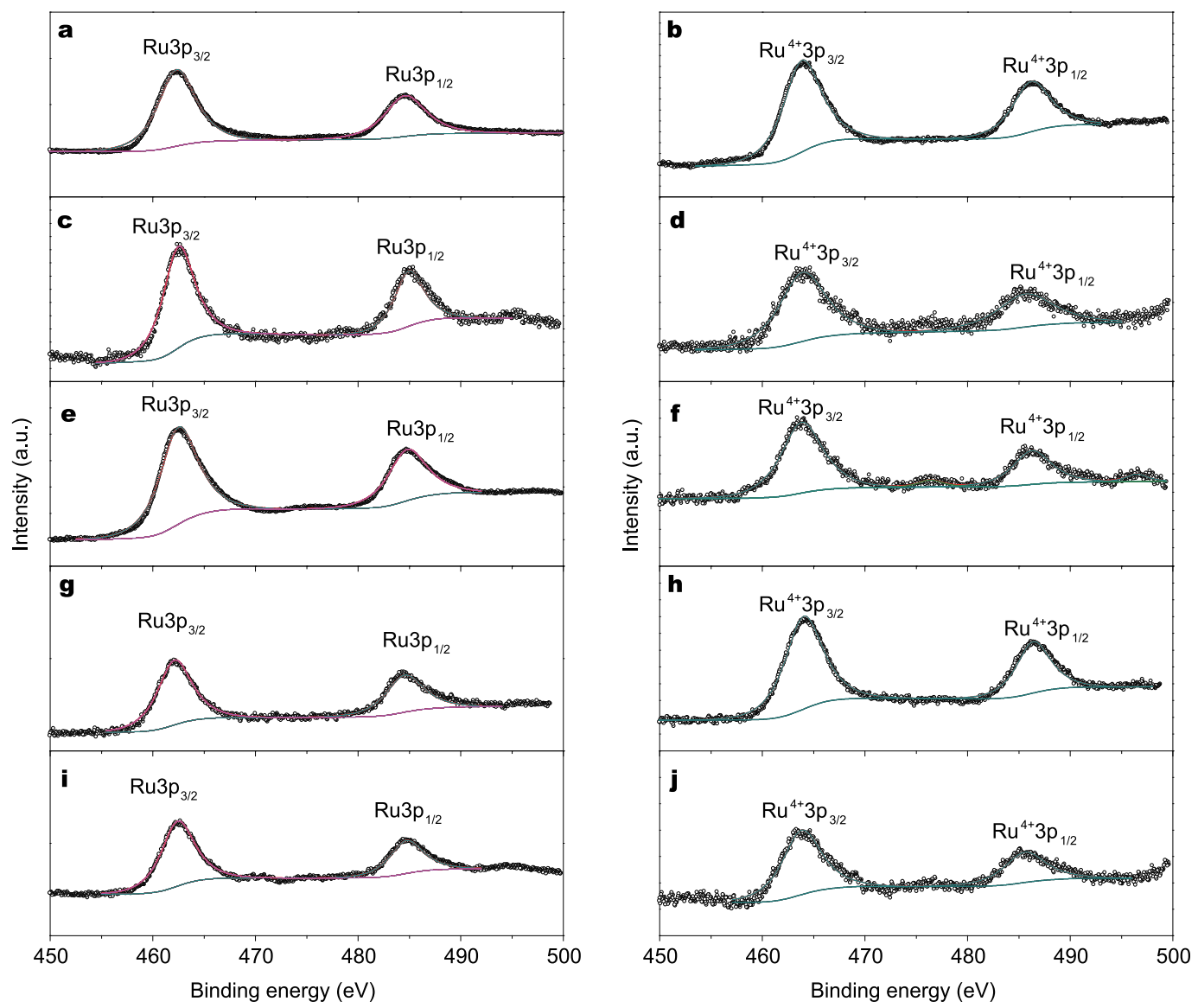

Figure 4 XPS spectra of the Ru in hCo-Ru (a, b), hCu-Ru (c, d), hFe-Ru (e, f), hNi-Ru (g, h), and hCuNi-Ru (i, j) before (a, c, e, g, i) and after calcination in air $(b, d, f, h, j)$, respectively. 
hCuNi-Ru, and $\mathrm{Ni}$ in hCuNi-Ru, respectively, suggest the successful conversion for the transition metals from zero valent metal to metal oxides, e.g., $\mathrm{CoO}, \mathrm{CuO}, \mathrm{Fe}_{2} \mathrm{O}_{3}$, and $\mathrm{NiO}[32,42]$.

In addition, the transformation for the transition metals and $\mathrm{Ru}$ from zero valent states to their oxidized states on the carbon or carbon nanotube supports could be further confirmed by XRD analyses. The XRD patterns of $\mathrm{hM}-\mathrm{Ru} / \mathrm{C}$ and $\mathrm{hM}-\mathrm{Ru} / \mathrm{CNT}$ before and after calcination in air are shown in Figs S4 and 5, respectively. As indicated, the homogeneously mixed crystal lattices, which indicate the formation of alloy nanoshells, in the XRD patterns for the $\mathrm{hM}-\mathrm{Ru} / \mathrm{C}$ and hM-Ru/CNT before calcination (a, c, e, $\mathrm{g}$, and $\mathrm{i}$ in Figs $\mathrm{S} 4$ and 5 for hCo- $\mathrm{Ru}, \mathrm{hCu}-\mathrm{Ru}, \mathrm{hFe}-\mathrm{Ru}$, $\mathrm{hNi}-\mathrm{Ru}$, and hCuNi-Ru, respectively) have been converted into mixed phases consisting of corresponding face-centered cubic (for $\mathrm{CoO}$ ), monoclinic (for $\mathrm{CuO}$ ), cubic (for $\mathrm{Fe}_{2} \mathrm{O}_{3}$ ), or hexagonal (for $\mathrm{NiO}$ ) transition metal oxides and tetragonal $\mathrm{RuO}_{2}$ after thermal treatment $(b, d, f, h$, and $\mathrm{j}$ in Figs $\mathrm{S} 4$ and 5 for hCo-Ru, hCu-Ru, hFe-Ru, hNi-Ru, and $\mathrm{hCuNi-Ru,} \mathrm{respectively).}$

The mass ratios of the transition metal oxides and $\mathrm{RuO}_{2}$ in the final $\mathrm{hMO}_{x}-\mathrm{RuO}_{2} / \mathrm{C}$ and $\mathrm{hMO}_{x}-\mathrm{RuO}_{2} / \mathrm{CNT}$ were determined by ICP-AES, and the results were summarized in Table S1. As shown, the $\mathrm{hCuO}-\mathrm{RuO}_{2}$ and $\mathrm{hCu} \mathrm{Cu}_{0.6} \mathrm{Ni}_{0.4} \mathrm{O}$ have lower contents of $\mathrm{MO}_{x}$ in comparison with those in other hollow nanostuructures. The complexity in the synthesis process, which involves the replacement reaction between TMNPs and Ru precursors, the oleylamine reduction of transition metal ions generated from galvanic replacement, the reduction of $\mathrm{Ru}$ ions added to the solution, and the alloying between $\mathrm{Ru}$ and transition metal atoms, may account for the different composition in the final hollow products. In specific, a molar ratio of $6 / 4$ is obtained for the $\mathrm{Cu}$ and $\mathrm{Ni}$ in ternary $\mathrm{hCuNiO}_{x}-\mathrm{RuO}_{2} / \mathrm{C}$ or $\mathrm{hCuNiO}_{x}-\mathrm{RuO}_{2} / \mathrm{CNT}$ product, which is slightly higher than the $\mathrm{Cu} / \mathrm{Ni}$ precursor ratio $(1 / 1)$ used to produce bimetallic $\mathrm{CuNi}$ seed particles.

The TEM images of the final $\mathrm{hMO}_{x}-\mathrm{RuO}_{2} / \mathrm{C}$ and $\mathrm{hMO}_{x}-\mathrm{RuO}_{2} / \mathrm{CNT}$ products are also exhibited in Fig. 3 (b, f, j, n, and $\mathrm{r}$ for carbon- and $\mathrm{d}, \mathrm{h}, \mathrm{l}, \mathrm{p}$, and $\mathrm{t}$ for carbon nanotube-supported hCoO- $\mathrm{RuO}_{2}, \mathrm{hCuO}-\mathrm{RuO}_{2}$, $h \mathrm{Fe}_{2} \mathrm{O}_{3}-\mathrm{RuO}_{2}, \mathrm{hNiO}-\mathrm{RuO}_{2}$, and $\mathrm{hCu}_{0.6} \mathrm{Ni}_{0.4} \mathrm{O}-\mathrm{RuO}_{2}$, respectively), which manifest that the resulting binary and ternary $\mathrm{hMO}_{x}-\mathrm{RuO}_{2}$ nanoparticles in the final products have the same size, size distribution, and hollow interiors as those of their hollow structured alloy precursors. In addition, the well dispersion of $\mathrm{hMO}_{x}-\mathrm{RuO}_{2}$ on the carbon or carbon nanotube supports is also maintained after calcination at elevated temperature in air.

The final $\mathrm{hMO}_{x}-\mathrm{RuO}_{2} / \mathrm{C}$ and $\mathrm{hMO}_{x}-\mathrm{RuO}_{2} / \mathrm{CNT}$ products were examined as electrode materials for a supercapacitor and benchmarked with the commercial $\mathrm{RuO}_{2} \cdot x \mathrm{H}_{2} \mathrm{O}$ from J\&K Scientific Ltd. The a and c series in Fig. 5 show the CVs of the as-prepared $\mathrm{hMO}_{x}-\mathrm{RuO}_{2}$ nanoparticles and commercial $\mathrm{RuO}_{2}$ supported on carbon (Figs $5 \mathrm{a}_{1}, \mathrm{a}_{2}, \mathrm{a}_{3}$, $\mathrm{a}_{4}, \mathrm{a}_{5}$, and $\mathrm{a}_{6}$ ) and carbon nanotubes (Figs $5 \mathrm{c}_{1}, \mathrm{c}_{2}, \mathrm{c}_{3}, \mathrm{c}_{4}$, $c_{5}$, and $c_{6}$ ) obtained in $6 \mathrm{~mol} \mathrm{~L}^{-1} \mathrm{KOH}$ with a potential range of $0-1.2 \mathrm{~V}$ at the scan rates of $20,50,100$, and 200 $\mathrm{mV} \mathrm{s}^{-1}$, respectively. For the same mass loading, the CV loops have different areas for different electrode materials, indicating different levels of stored charge. In general, the metal oxides usually display redox reaction. However, the $\mathrm{RuO}_{2}$ has multiple continuous redox peaks, which are overlaying together to show double-layer-like capacitor. Further, because of the different pseudocapacitance of $\mathrm{MO}_{x}$, the $\mathrm{hMO}_{x}-\mathrm{RuO}_{2}$ hollow nanosturctures exhibit various redox features. In comparison with those of other $\mathrm{hMO}_{x}-\mathrm{RuO}_{2}$ and commercial $\mathrm{RuO}_{2}$ samples, the $\mathrm{CV}$ curves of hCoO- $\mathrm{RuO}_{2}$ (Figs $5 \mathrm{a}_{1}$ and $\mathrm{c}_{1}$ ) and $\mathrm{hNiO}-\mathrm{RuO}_{2}$ (Figs $5 \mathrm{a}_{4}$ and $c_{4}$ ) supported on carbon (Figs $5 \mathrm{a}_{1}$ and $\mathrm{a}_{4}$ ) and carbon nanotubes (Figs $5 c_{1}$ and $c_{4}$ ) have obvious redox peaks, clearly illustrating their typical pseudocapactive mechanism. In specific, besides more rectangle shapes, which usually reveals perfect electrochemical reversibility of the Faradaic redox transitions on the surface of oxides, both $\mathrm{hNiO}-\mathrm{RuO}_{2} / \mathrm{C}$ and $\mathrm{hNiO}-\mathrm{RuO}_{2} / \mathrm{CNT}$ electrodes (Figs $5 \mathrm{a}_{4}$ and $c_{4}$, respectively) exhibit much higher current densities than those of other carbon or carbon nanotube-supported $\mathrm{hMO}_{x}-\mathrm{RuO}_{2}$ and commercial $\mathrm{RuO}_{2}$ samples, suggesting that they have higher electrochemical capacitance.

The specific capacitances calculated from the CV loops for the $\mathrm{hMO}_{x}-\mathrm{RuO}_{2} / \mathrm{C}, \mathrm{hMO}_{x}-\mathrm{RuO}_{2} / \mathrm{CNT}$, and commercial $\mathrm{RuO}_{2}$ samples, which are summarized in Table S2, exhibit decreased trend with the increase of scan rates owing to the limited rate of ion diffusion at high scan rates. As evinced, the specific capacitances of most $\mathrm{hMO}_{x}-\mathrm{RuO}_{2}$ products are comparable with that of commercial $\mathrm{RuO}_{2}$ samples, particularly at high scan rates, although the mass ratios of $\mathrm{RuO}_{2}$ in these binary or ternary hollow structures are less than $40 \%$. In particular, the specific capacitance value for the supercapacitors based on $\mathrm{hNiO}-\mathrm{RuO}_{2} / \mathrm{CNT}$ electrode can reach $947.1 \mathrm{~F} \mathrm{~g}^{-1}$ (based on total mass of metal oxides) at scan rate of $20 \mathrm{mV} \mathrm{s}^{-1}$. This value is much higher than the recent data reported for $\mathrm{RuO}_{2}$-based electrodes, e.g., 642 $\mathrm{F} \mathrm{g}^{-1}$ for the mesoporous $\mathrm{Co}_{3} \mathrm{O}_{4} / \mathrm{RuO}_{2} \cdot x \mathrm{H}_{2} \mathrm{O}$ composites [22], 162.4 $\mathrm{F} \mathrm{g}^{-1}$ for the $\mathrm{MnO}_{x}-\mathrm{RuO}_{2}$ nanofiber mats [23], $173.2 \mathrm{~F} \mathrm{~g}^{-1}$ for the electro-spun $\mathrm{RuO}_{2}-\mathrm{Ag}_{2} \mathrm{O}$ composite 

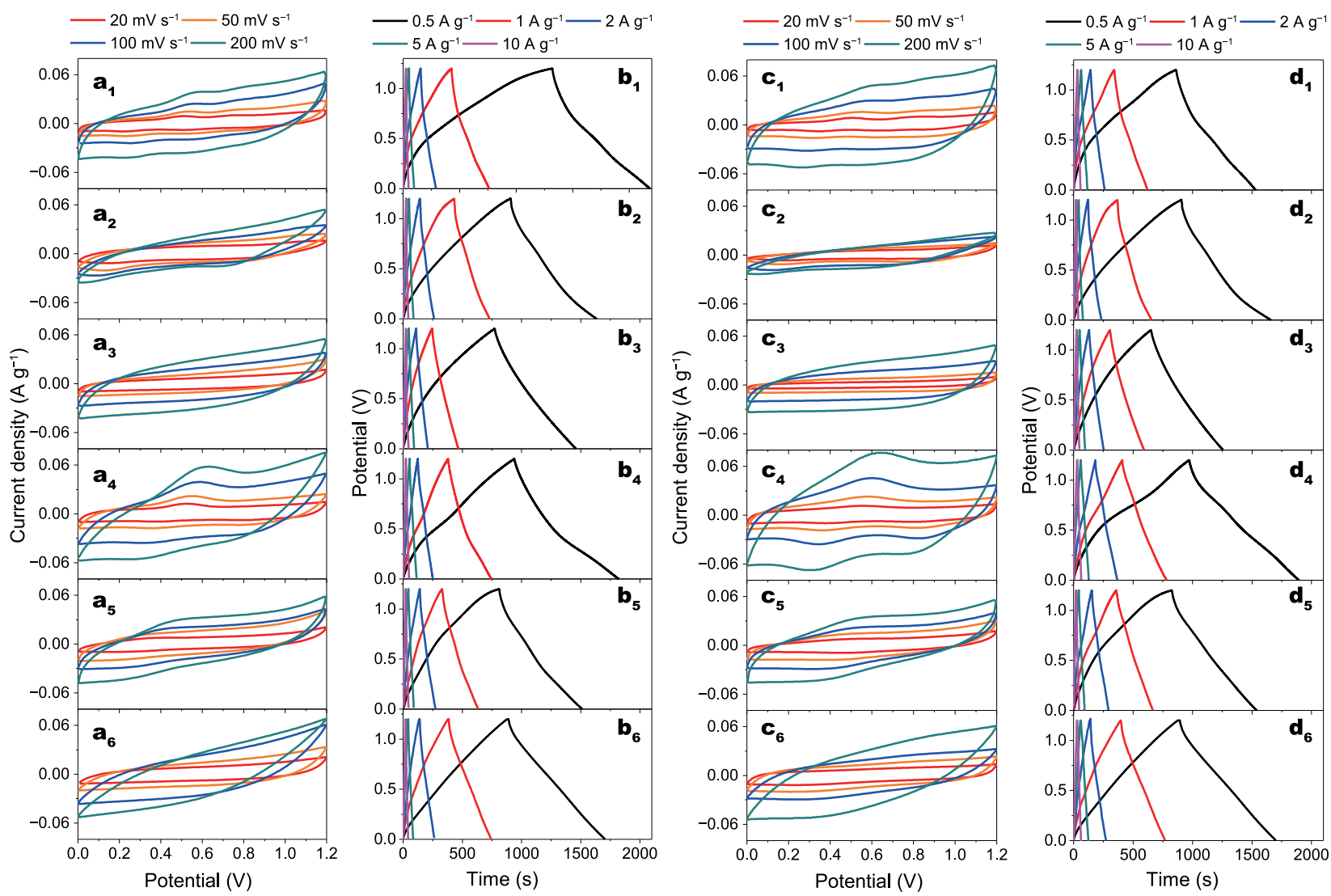

Figure 5 Cyclic voltammograms of hCoO- $\mathrm{RuO}_{2}\left(\mathrm{a}_{1}, \mathrm{c}_{1}\right), \mathrm{hCuO}-\mathrm{RuO}_{2}\left(\mathrm{a}_{2}, \mathrm{c}_{2}\right), \mathrm{hFe}_{2} \mathrm{O}_{3}-\mathrm{RuO}_{2}\left(\mathrm{a}_{3}, \mathrm{c}_{3}\right), \mathrm{hNiO}-\mathrm{RuO}_{2}\left(\mathrm{a}_{4}, \mathrm{c}_{4}\right), \mathrm{hCu} \mathrm{h}_{0.6} \mathrm{Ni}_{0.4} \mathrm{O}-\mathrm{RuO}_{2}\left(\mathrm{a}_{5}, \mathrm{c}_{5}\right)$, and commercial $\mathrm{RuO}_{2}\left(\mathrm{a}_{6}, \mathrm{c}_{6}\right)$ supported on carbon $\left(\mathrm{a}_{1}, \mathrm{a}_{2}, \mathrm{a}_{3}, \mathrm{a}_{4}, \mathrm{a}_{5}, \mathrm{a}_{6}\right)$ and carbon nanotubes $\left(\mathrm{c}_{1}, \mathrm{c}_{2}, \mathrm{c}_{3}, \mathrm{c}_{4}, \mathrm{c}_{5}, \mathrm{c}_{6}\right)$ at different scan rates; galvanostatic chargedischarge curves of hCoO- $\mathrm{RuO}_{2}\left(\mathrm{~b}_{1}, \mathrm{~d}_{1}\right), \mathrm{hCuO}-\mathrm{RuO}_{2}\left(\mathrm{~b}_{2}, \mathrm{~d}_{2}\right), \mathrm{hFe}_{2} \mathrm{O}_{3}-\mathrm{RuO}_{2}\left(\mathrm{~b}_{3}, \mathrm{~d}_{3}\right), \mathrm{hNiO}-\mathrm{RuO}_{2}\left(\mathrm{~b}_{4}, \mathrm{~d}_{4}\right), \mathrm{hCu}_{0.6} \mathrm{Ni}_{0.4} \mathrm{O}-\mathrm{RuO}_{2}\left(\mathrm{~b}_{5}, \mathrm{~d}_{5}\right)$, and commercial $\mathrm{RuO}_{2}\left(\mathrm{~b}_{6}, \mathrm{~d}_{6}\right)$ supported on carbon $\left(\mathrm{b}_{1}, \mathrm{~b}_{2}, \mathrm{~b}_{3}, \mathrm{~b}_{4}, \mathrm{~b}_{5}, \mathrm{~b}_{6}\right)$ and carbon nanotubes $\left(\mathrm{d}_{1}, \mathrm{~d}_{2}, \mathrm{~d}_{3}, \mathrm{~d}_{4}, \mathrm{~d}_{5}, \mathrm{~d}_{6}\right)$ at different current densities.

nanowires [24], $590 \mathrm{~F} \mathrm{~g}^{-1}$ for the $\mathrm{Co}_{3} \mathrm{O}_{4} @ \mathrm{RuO}_{2}$ nanosheet arrays on carbon cloth [25], $905 \mathrm{~F} \mathrm{~g}^{-1}$ for the $\mathrm{RuO}_{2}$ nanoparticle decorated mesoporous $\mathrm{Co}_{3} \mathrm{O}_{4}$ nanosheet [26], $620 \mathrm{~F} \mathrm{~g}^{-1}$ for the $\mathrm{Ru}$-Co mixed oxide deposited on single-walled carbon nanotubes [43], and $710 \mathrm{~F} \mathrm{~g}^{-1}$ for the $\mathrm{SnO}_{2}-\mathrm{RuO}_{2}$ composite films (based on pure $\mathrm{RuO}_{2}$ not the total composite) [44]. Even at a high scan rate of 200 $\mathrm{mV} \mathrm{s}^{-1}$, the $\mathrm{hNiO}-\mathrm{RuO}_{2} / \mathrm{CNT}$ electrode still yields a high capacitance of $533.9 \mathrm{~F} \mathrm{~g}^{-1}$. The better capacitive behavior of $\mathrm{hMO}_{x}-\mathrm{RuO}_{2} / \mathrm{C}$ and $\mathrm{hMO}_{x}-\mathrm{RuO}_{2} / \mathrm{CNT}$ products in comparison with that of other $\mathrm{RuO}_{2}$-based electrodes and commercial $\mathrm{RuO}_{2}$ might be attributed to the large surface area of the hollow structures, where the discontinuous shells allow the internal surface of the binary and ternary $\mathrm{hMO}_{x}-\mathrm{RuO}_{2}$ nanoparticles to be accessible for the multiple redox reactions. In addition, the relatively short diffusion distance for the ions in the thin shell of $\mathrm{hMO}_{x}-\mathrm{RuO}_{2}$ samples would also be helpful for enhancing the electro-active sites.

It is noteworthy that although carbon nanotubes usually have superior electronic conductivity, the binary or ternary hollow nanostructures supported on them do not always show higher specific capacitance than that of their counterparts supported on carbon powders. This is because in addition to the electronic conductivity of the supports, the specific capacitance is also associated with the interaction between active materials and substrates and the dispersity of the active materials on the surface of substrates.

To further identify the electrochemical performance of all carbon and carbon nanotube-supported $\mathrm{hMO}_{x}-\mathrm{RuO}_{2}$ products as electrodes for supercapacitors, the galvanostatic charge-discharge measurements were conducted at current densities of $0.5,1,2,5$, and $10 \mathrm{~A} \mathrm{~g}^{-1}$. As shown in $\mathrm{b}$ and $\mathrm{d}$ of Fig. 5 for the galvanostatic charge-discharge curves of $\mathrm{hMO}_{x}-\mathrm{RuO}_{2}$ and commercial $\mathrm{RuO}_{2}$ samples supported on carbon and carbon nanotubes, respectively, the almost triangular shapes at each current density indicate their good electrochemical reversibility within a stable potential window of $0-1.2 \mathrm{~V}$ because of the high degree of symmetry in charge and discharge. In specific, for the 
hNiO- $\mathrm{RuO}_{2} / \mathrm{C}$ (Fig. 5b $\mathrm{b}_{4}$ ) and $\mathrm{hNiO}-\mathrm{RuO}_{2} / \mathrm{CNT}$ samples (Fig. $5 \mathrm{~d}_{4}$ ), slight plateaus appearing during the charge-discharge process further verify their pseudo-capacitance behavior, which corresponds well with the CV curves.

Figs $6 \mathrm{a}$ and $\mathrm{b}$ show the specific capacitances of $\mathrm{hMO}_{x^{-}}$ $\mathrm{RuO}_{2}$ and commercial $\mathrm{RuO}_{2}$ supported on carbon and carbon nanotubes at the current density of $0.5,1,2$, and 5 $\mathrm{A} \mathrm{g}^{-1}$, respectively, which are calculated based on the total mass of oxides. The specific capacitances measured at different current densities for $\mathrm{hMO}_{x}-\mathrm{RuO}_{2}$ and commercial $\mathrm{RuO}_{2}$ supported on carbon or carbon nanotubes are listed in Table S3. Again, the $\mathrm{hNiO}-\mathrm{RuO}_{2} / \mathrm{C}$ and $\mathrm{hNiO}-$ $\mathrm{RuO}_{2} / \mathrm{CNT}$ exhibit higher capacitances at all current densities $\left(758.8,686.4,625.8,550.0 \mathrm{~F} \mathrm{~g}^{-1}\right.$ for $\mathrm{hNiO}-\mathrm{RuO}_{2} / \mathrm{C}$ and 792.1, 740.0, 704.5, and 638.4 $\mathrm{F} \mathrm{g}^{-1}$ for $\mathrm{hNiO}-\mathrm{RuO}_{2} / \mathrm{CNT}$ at current density of $0.5,1,2$, and $5 \mathrm{~A} \mathrm{~g}^{-1}$, respectively) than those of other $\mathrm{hMO}_{x}-\mathrm{RuO}_{2}$ as well as the commercial
$\mathrm{RuO}_{2}$ supported on the same substrates. The optimized microstructure in terms of nano-channels in the particle shell, shell thickness, and surface morphology, interaction and mass ratio between $\mathrm{RuO}_{2}$ and transition metal oxide, and the distribution of the hollow oxides over the substrates may account for the superior specific capacitance for this sample.

The cycle life is another important factor for evaluating the performance of electrode materials for a supercapacitor. The comparison of the long-term cycling performance of the electrode materials at constant current density of $1 \mathrm{~A} \mathrm{~g} \mathrm{~g}^{-1}$ is illustrated in Figs $6 \mathrm{c}$ and $\mathrm{d}$ for carbon and carbon nanotube as substrates, respectively. The specific capacitance retention ratios after 2000 cycles, which are calculated from Figs $6 a$ and $b$, are presented in Table $\mathrm{S} 4$. As shown, except for $\mathrm{hNiO}-\mathrm{RuO}_{2} / \mathrm{C}$ and $\mathrm{hCu}_{0.6} \mathrm{Ni}_{0.4} \mathrm{O}-$ $\mathrm{RuO}_{2} / \mathrm{C}$, which have $88.2 \%$ and $85.6 \%$ retention of their ini-
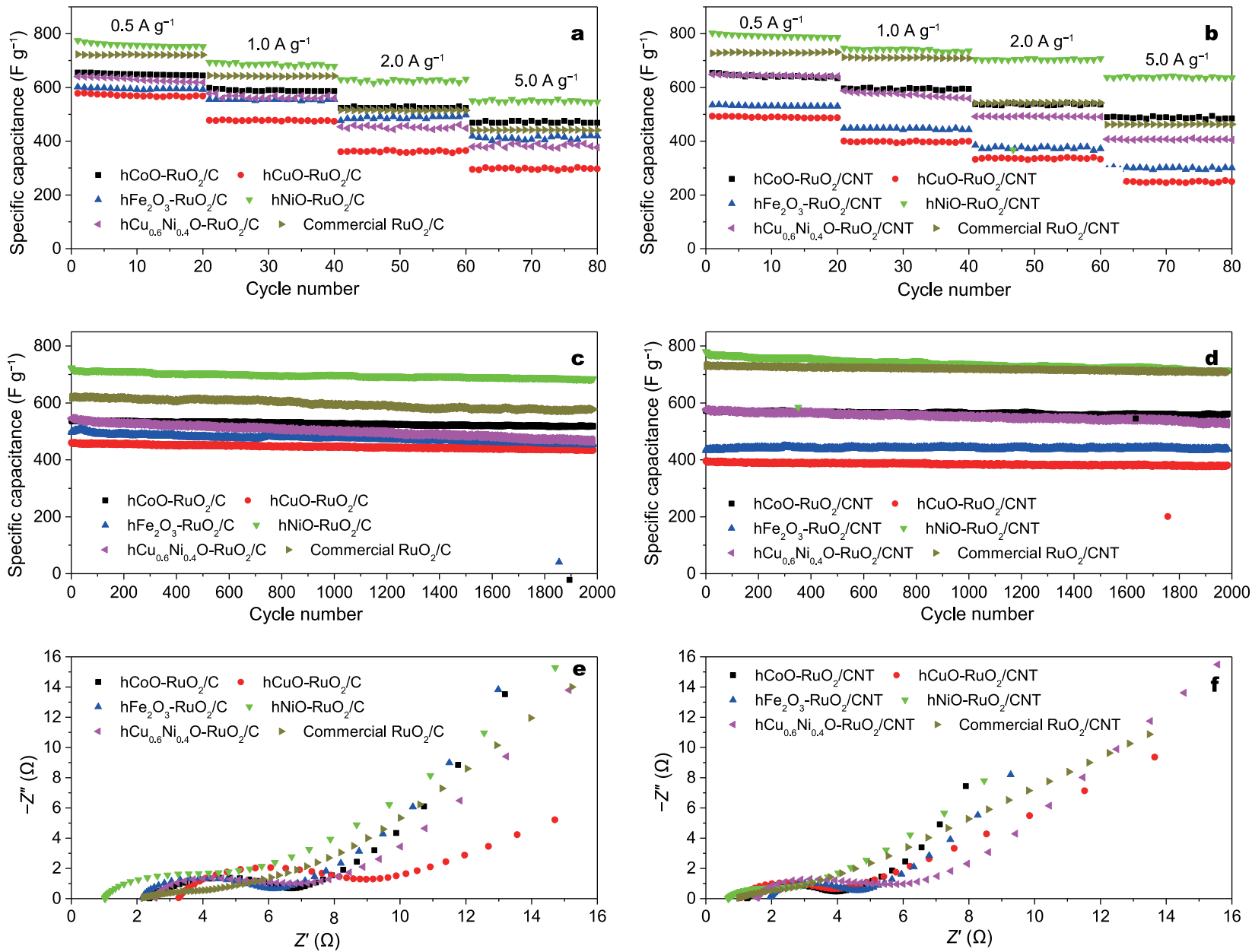

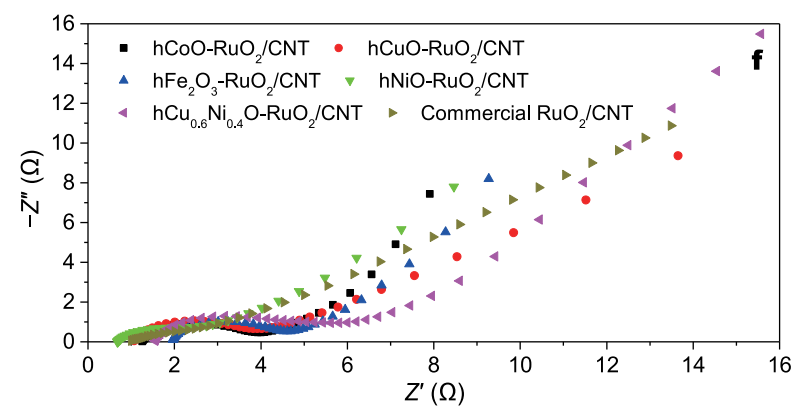

Figure 6 Plots of specific capacitance for $\mathrm{hMO}_{x}-\mathrm{RuO}_{2}$ and commercial $\mathrm{RuO}_{2}$ supported on carbon (a) and carbon nanotubes (b) at different current densities; comparison of the long-term cycling performance of $\mathrm{hMO}_{x}-\mathrm{RuO}_{2}$ and commercial $\mathrm{RuO}_{2}$ supported on carbon (c) and carbon nanotubes (d) at current density of $1 \mathrm{~A} \mathrm{~g}^{-1}$; comparison of Nyquist plots for $\mathrm{hMO}_{x}-\mathrm{RuO}_{2}$ and commercial $\mathrm{RuO}_{2}$ supported on carbon (e) and carbon nanotubes (f). 
tial capacitances, other $\mathrm{hMO}_{x}-\mathrm{RuO}_{2} / \mathrm{C}$ and $\mathrm{hMO}_{x^{-}}$ $\mathrm{RuO}_{2} / \mathrm{CNT}$ electrode materials exhibit excellent stability with at least $91.2 \%$ retention of the initial capacitance $\left(\mathrm{hFe}_{2} \mathrm{O}_{3}-\mathrm{RuO}_{2} / \mathrm{C}\right)$. These retention ratios at constant current density are comparable and even better than those of the commercial $\mathrm{RuO}_{2}$ supported on carbon (94.5\%) or carbon nanotubes $(97.2 \%)$. In particular, the specific capacitance retention ratios after 5000 cycles for $\mathrm{hCoO}-\mathrm{RuO}_{2} / \mathrm{C}, \mathrm{hCoO}-\mathrm{RuO}_{2} / \mathrm{CNT}, \mathrm{hNiO}-\mathrm{RuO}_{2} / \mathrm{C}$, and $\mathrm{hNiO}-\mathrm{RuO}_{2} / \mathrm{CNT}$ were also tested, which are $93.9 \%$, $94.1 \%, 88.0 \%$ and $89.8 \%$, respectively, as exhibited by Fig. S6. The high cycling stability might have also benefited from the hollow interiors of the binary or ternary metal oxides, which could alleviate the strain effect developed during the frequent charge-discharge process.

The specific power density $(P)$ and energy density $(E)$ were calculated using the following equations:

$$
\begin{gathered}
P=V^{2} / 4 m R, \\
E=C V^{2} / 2,
\end{gathered}
$$

where $P$ and $E$ are the specific power density $\left(\mathrm{kW} \mathrm{kg}^{-1}\right)$ and energy density $\left(\mathrm{W} \mathrm{h} \mathrm{kg}^{-1}\right)$, respectively, $V$ is the maximum potential $(\mathrm{V}), R$ is the equivalent series resistance $(\Omega), m$ is the mass of the electro-active materials in the capacitor $(\mathrm{g})$, and $C$ is the specific capacitance $\left(\mathrm{F} \mathrm{g}^{-1}\right)$. As listed in Table $\mathrm{S} 5$, in this work, the equivalent series resistances of the capacitors based on hCoO- $\mathrm{RuO}_{2} / \mathrm{C}, \mathrm{hCoO}-\mathrm{RuO}_{2} / \mathrm{CNT}$, $\mathrm{hCuO}-\mathrm{RuO}_{2} / \mathrm{C}, \quad \mathrm{hCuO}-\mathrm{RuO}_{2} / \mathrm{CNT}, \quad \mathrm{hFe}_{2} \mathrm{O}_{3}-\mathrm{RuO}_{2} / \mathrm{C}$, $\mathrm{hFe}_{2} \mathrm{O}_{3}-\mathrm{RuO}_{2} / \mathrm{CNT}, \quad \mathrm{hNiO}-\mathrm{RuO}_{2} / \mathrm{C}, \mathrm{hNiO}-\mathrm{RuO}_{2} / \mathrm{CNT}$, $\mathrm{hCu}_{0.6} \mathrm{Ni}_{0.4} \mathrm{O}-\mathrm{RuO}_{2} / \mathrm{C}, \mathrm{hCu}_{0.6} \mathrm{Ni}_{0.4} \mathrm{O}-\mathrm{RuO}_{2} / \mathrm{CNT}$, commercial $\mathrm{RuO}_{2} / \mathrm{C}$, and commercial $\mathrm{RuO}_{2} / \mathrm{CNT}$ are $2.37,1.26$, $3.27,1.07,2.18,1.97,1.03,0.68,2.54,1.55,1.19$, and 1.01 $\Omega$, respectively. Calculations by the Equations (2 and 3) above indicate that the specific power densities $(P)$ for the capacitor based on $\mathrm{hCoO}-\mathrm{RuO}_{2} / \mathrm{C}, \mathrm{hCoO}-\mathrm{RuO}_{2} / \mathrm{CNT}$, $\mathrm{hCuO}-\mathrm{RuO}_{2} / \mathrm{C}, \mathrm{hCuO}-\mathrm{RuO}_{2} / \mathrm{CNT}, \quad \mathrm{hFe}_{2} \mathrm{O}_{3}-\mathrm{RuO}_{2} / \mathrm{C}$, $\mathrm{hFe}_{2} \mathrm{O}_{3}-\mathrm{RuO}_{2} / \mathrm{CNT}, \quad \mathrm{hNiO}-\mathrm{RuO}_{2} / \mathrm{C}, \mathrm{hNiO}-\mathrm{RuO}_{2} / \mathrm{CNT}$, $\mathrm{hCu}_{0.6} \mathrm{Ni}_{0.4} \mathrm{O}-\mathrm{RuO}_{2} / \mathrm{C}, \mathrm{hCu}_{0.6} \mathrm{Ni}_{0.4} \mathrm{O}-\mathrm{RuO}_{2} / \mathrm{CNT}$, commercial $\mathrm{RuO}_{2} / \mathrm{C}$, and commercial $\mathrm{RuO}_{2} / \mathrm{CNT}$ are 38.0, 71.4, $27.5,84.1,41.3,45.7,87.4,132.4,35.4,58.1,75.6$, and 90.0 $\mathrm{W} \mathrm{kg}^{-1}$, respectively, while the energy densities $(E)$ are $129.8,128.4,136.2,136.4,119.0,106.2,151.8,158.4,125.9$, $128.8,144.3$, and $145.9 \mathrm{Wh} \mathrm{kg}^{-1}$, respectively, which are also placed in Table S5. Notably, there are two features could be observed from Table S5: the samples supported on carbon nanotubes have lower series resistances than those of the same supported on carbon substrates; the $\mathrm{hNiO}-\mathrm{RuO}_{2} / \mathrm{CNT}$ has the lowest series resistance among all electrode materials. Therefore, the supercapacitor based on $\mathrm{hNiO}-\mathrm{RuO}_{2} / \mathrm{CNT}$ has the highest power and energy densities, which are $132.4 \mathrm{~W} \mathrm{~kg}^{-1}$ and $158.4 \mathrm{Wh} \mathrm{kg}^{-1}$, respectively, essentially in keeping with its high specific capacitance.

Figs 6e and $\mathrm{f}$ show the Nyquist plots of the $\mathrm{hMO}_{x}-\mathrm{RuO}_{2}$ and commercial $\mathrm{RuO}_{2}$ supported on carbon and carbon nanotubes, respectively, measured by EIS, which illustrate the frequency response of the electrode/electrolyte system. In the low-frequency area, the line slope in the EIS plots indicates Warburg impedance, which is caused by ionic diffusion, and could be governed by the physical characters of the electrode materials, e.g., particle size, specific surface area, and diffusion distance. The more vertical the curve, the more closely the supercapacitor behaves as an ideal capacitor. As shown in the Nyquist plots, in the low-frequency area the curves of the $\mathrm{hCoO}-\mathrm{RuO}_{2} / \mathrm{C}$ and $\mathrm{hNiO}-\mathrm{RuO}_{2} / \mathrm{C}$ (Fig. 6e) as well as the $\mathrm{hCoO}-\mathrm{RuO}_{2} / \mathrm{CNT}$ and $\mathrm{hNiO}-\mathrm{RuO}_{2} / \mathrm{CNT}$ (Fig. 6f) are more vertical to the $x$ axis than those of other carbon or carbon nanotube-supported hollow oxides and commercial $\mathrm{RuO}_{2}$, indicating a significant enhancement of the charge transport in $\mathrm{hCoO}-\mathrm{RuO}_{2} / \mathrm{C}, \mathrm{hNiO}-\mathrm{RuO}_{2} / \mathrm{C}, \mathrm{hCoO}-\mathrm{RuO}_{2} / \mathrm{CNT}$, and $\mathrm{hNiO}-\mathrm{RuO}_{2} / \mathrm{CNT}$ electrodes. In the high-frequency area, the interception of the curve in the real part $Z$ indicates the bulk resistance of the electrochemical system. Obviously, the $\mathrm{hNiO}-\mathrm{RuO}_{2} / \mathrm{C}$ and $\mathrm{hNio}-\mathrm{RuO}_{2} / \mathrm{CNT}$ electrodes display very low bulk resistance.

Finally, as a vivid demonstration of the application of these hollow structured binary or ternary metal oxides, we fabricated three symmetric cells, which were consisted of $\mathrm{hCoO}-\mathrm{RuO}_{2} / \mathrm{C}, \mathrm{hCuO}-\mathrm{RuO}_{2} / \mathrm{C}$, and $\mathrm{hNiO}-\mathrm{RuO}_{2} / \mathrm{C}$ electrodes, respectively. These cells were charged at a constant voltage of $1.2 \mathrm{~V}$ for $5 \mathrm{~min}$, and then were connected in series to run a white light emitting diode (LED, $5 \mathrm{~mm}, 3.0$ V, $30 \mathrm{~mA}$ ), as illustrated in Fig. S7. We noticed that the LED remains very bright even after 30 min of operation, manifesting application potentials of these hollow binary or ternary Ru-based oxides in practical supercapacitors.

\section{CONCLUSION}

In summary, we reported a general approach based on the combination of the galvanic replacement process with a subsequent thermal treatment to produce carbon or carbon nanotube-supported hollow nanostructures of $\mathrm{Ru}$-based binary or ternary oxides as highly efficient electrodes for supercapacitors. This strategy involves the synthesis of the transition metal nanoparticles including $\mathrm{Co}, \mathrm{Cu}, \mathrm{Fe}, \mathrm{Ni}$, or $\mathrm{CuNi}$, and subsequent replacement reaction with $\mathrm{Ru}$ ion precursors for the preparation of binary or ternary hollow 
nanostructures composed of corresponding transition metal and $\mathrm{Ru}$, which are then loaded on carbon or carbon nanotube substrates and subjected to a thermal treatment in air to generate binary or ternary Ru-based metal oxides with hollow interiors. The as-prepared Ru-based hollow oxides show superior performance as electrodes for a supercapacitor. Specifically, the binary hollow nanostructures composed of $\mathrm{NiO}$ and $\mathrm{RuO}_{2}$ supported on carbon nanotubes with $\mathrm{RuO}_{2}$ mass ratio of $19.6 \%$ exhibit high specific capacitances of $740.0 \mathrm{~F} \mathrm{~g}^{-1}$ with good cycle stability at a current density of $1 \mathrm{~A} \mathrm{~g}^{-1}$ in a symmetric capacitor adopting $\mathrm{KOH}$ as electrolyte, much higher than that of commercial $\mathrm{RuO}_{2}$ supported on the same substrates (620.1 $\mathrm{F}^{-1}$ ). The hollow interiors formed during the galvanic replacement process not only enhance the electro-active sites by increasing the specific surface area of $\mathrm{RuO}_{2}$-based binary and ternary electrodes, but also facilitate the charge transport in the electro-active materials by shortening the diffusion distance. The concept used to fabricate hollow structured binary or ternary Ru-based oxides might be extended to produce other multiple metal oxides as highly efficient electrode materials for a supercapacitor.

\section{Received 26 April 2016; accepted 20 May 2016;} published online 30 May 2016

1 Zhao DD, Bao SJ, Zhou WH, et al. Preparation of hexagonal nanoporous nickel hydroxide film and its application for electrochemical capacitor. Electrochem Commun, 2007, 9: 869-874

2 Patake VD, Lokhande CD, Joo OS. Electrodeposited ruthenium oxide thin films for supercapacitor: effect of surface treatments. Appl Surf Sci, 2009, 255: 4192-4196

3 Brezesinski T, Wang J, Tolbert SH, et al. Ordered mesoporous $\mathrm{a}-\mathrm{MoO}_{3}$ with iso-oriented nanocrystalline walls for thin-film pseudocapacitors. Nat Mater, 2010, 9: 146-151

$4 \mathrm{Wu} \mathrm{Q}, \mathrm{Xu} \mathrm{Y}$, Yao Z, et al. Supercapacitors based on flexible graphene/polyaniline nanofiber composite films. ACS Nano, 2010, 4: $1963-1970$

5 Wang K, Huang J, Wei Z. Conducting polyaniline nanowire arrays for high performance supercapacitors. J Phys Chem C, 2010, 114: 8062-8067

6 Lang X, Hirata A, Fujita T, et al. Nanoporous metal/oxide hybrid electrodes for electrochemical supercapacitors. Nat Nanotechnol, 2011, 6: 232-236

7 Yan D, Guo Z, Zhu G, et al. $\mathrm{MnO}_{2}$ film with three-dimensional structure prepared by hydrothermal process for supercapacitor. J Power Sources, 2012, 199: 409-412

8 Simon P, Gogotsi Y. Materials for electrochemical capacitors. Nat Mater, 2008, 7: 845-854

9 Wang G, Zhang L, Zhang J. A review of electrode materials for electrochemical supercapacitors. Chem Soc Rev, 2012, 41: 797-828

10 Liu S, Sun S, You XZ. Inorganic nanostructured materials for high performance electrochemical supercapacitors. Nanoscale, 2014, 6: 2037-2045

11 Soin N, Roy SS, Mitra SK, et al. Nanocrystalline ruthenium oxide dispersed few layered graphene (FLG) nanoflakes as supercapacitor electrodes. J Mater Chem, 2012, 22: 14944-14950

12 Chen LY, Hou Y, Kang JL, et al. Toward the theoretical capacitance of $\mathrm{RuO}_{2}$ reinforced by highly conductive nanoporous gold. Adv Energy Mater, 2013, 3: 851-856

13 Ananth A, Dharaneedharan S, Gandhi MS, et al. Novel $\mathrm{RuO}_{2}$ nanosheets-facile synthesis, characterization and application. Chem Eng J, 2013, 223: 729-736

14 Kim JY, Kim KH, Kim HK, et al. Nanosheet-assembled 3D nanoflowers of ruthenium oxide with superior rate performance for supercapacitor applications. RSC Adv, 2014, 4: 16115-16120

15 Pico F, Ibañez J, Lillo-Rodenas MA, et al. Understanding $\mathrm{RuO}_{2} \cdot x \mathrm{H}_{2} \mathrm{O} /$ carbon nanofibre composites as supercapacitor electrodes. J Power Sources, 2008, 176: 417-425

$16 \mathrm{Wu} \mathrm{ZS}$, Wang DW, Ren W, et al. Anchoring hydrous $\mathrm{RuO}_{2}$ on graphene sheets for high-performance electrochemical capacitors. Adv Funct Mater, 2010, 20: 3595-3602

17 Zhang J, Jiang J, Li H, et al. A high-performance asymmetric supercapacitor fabricated with graphene-based electrodes. Energy Environ Sci, 2011, 4: 4009-4015

18 Fang HT, Liu M, Wang DW, et al. Fabrication and supercapacitive properties of a thick electrode of carbon nanotube- $\mathrm{RuO}_{2}$ core-shell hybrid material with a high $\mathrm{RuO}_{2}$ loading. Nano Energy, 2013, 2: $1232-1241$

19 Zhou Z, Zhu Y, Wu Z, et al. Amorphous $\mathrm{RuO}_{2}$ coated on carbon spheres as excellent electrode materials for supercapacitors. RSC Adv, 2014, 4: 6927-6932

20 Kim H, Popov BN. Characterization of hydrous ruthenium oxide/carbon nanocomposite supercapacitors prepared by a colloidal method. J Power Sources, 2002, 104: 52-61

21 Pico F, Morales E, Fernandez JA, et al. Ruthenium oxide/carbon composites with microporous or mesoporous carbon as support and prepared by two procedures. A comparative study as supercapacitor electrodes. Electrochim Acta, 2009, 54: 2239-2245

22 Liu Y, Zhao W, Zhang X. Soft template synthesis of mesoporous $\mathrm{Co}_{3} \mathrm{O}_{4} / \mathrm{RuO}_{2} \cdot x \mathrm{H}_{2} \mathrm{O}$ composites for electrochemical capacitors. Electrochim Acta, 2008, 53: 3296-3304

23 Hyun TS, Kang JE, Kim HG, et al. Electrochemical properties of $\mathrm{MnO}_{x}-\mathrm{RuO}_{2}$ nanofiber mats synthesized by co-electrospinning. Electrochem Solid-Sate Lett, 2009, 12: A225-A228

24 Lee JB, Jeong SY, Moon WJ, et al. Preparation and characterization of electro-spun $\mathrm{RuO}_{2}-\mathrm{Ag}_{2} \mathrm{O}$ composite nanowires for electrochemical capacitors. J Alloy Compd, 2011, 509: 4336-4340

25 Xu J, Wang Q, Wang X, et al. Flexible asymmetric supercapacitors based upon $\mathrm{Co}_{9} \mathrm{~S}_{8}$ nanorod $/ \mathrm{Co}_{3} \mathrm{O}_{4} @ \mathrm{RuO}_{2}$ nanosheet arrays on carbon cloth. ACS Nano, 2013, 7: 5453-5462

26 Rakhi RB, Chen W, Hedhili MN, et al. Enhanced rate performance of mesoporous $\mathrm{Co}_{3} \mathrm{O}_{4}$ nanosheet supercapacitor electrodes by hydrous $\mathrm{RuO}_{2}$ nanoparticle decoration. ACS Appl Mater Interfaces, 2014, 6: 4196-4206

27 Ghosh A, Lee YH. Carbon-based electrochemical capacitors. ChemSusChem, 2012, 5: 480-499

28 Zhi M, Xiang C, Li J, et al. Nanostructured carbon-metal oxide composite electrodes for supercapacitors: a review. Nanoscale, 2013, 5: $72-88$

29 Liu X, Atwater M, Wang J, et al. A study on gold nanoparticle synthesis using oleylamine as both reducing agent and protecting ligand. J Nanosci Nanotechnol, 2007, 7: 3126-3133

$30 \mathrm{Xu} \mathrm{Z}$, Shen $\mathrm{C}$, Hou Y, et al. Oleylamine as both reducing agent and stabilizer in a facile synthesis of magnetite nanoparticles. Chem Mater, 2009, 21: 1778-1780

31 Stefanos M, Liz-Marzan LM. Oleylamine in nanoparticle synthesis. Chem Mater, 2013, 25: 1465-1476 
32 Moulder JF, Chastain J. Handbook of X-ray Photoelectron Spectroscopy. A Reference Book of Standard Spectra for Identification and Interpretation of XPS Data. Eden Prairie Minnesota: Physical Electronics Division Perkin-Elmer Corp, 1992

33 Powell CJ. Recommended Auger parameters for 42 elemental solids. J Electron Spectrosc Relat Phenom, 2012, 185: 1-3

34 Conner GR. Combination analysis of metal oxides using ESCA, AES, and SIMS. J Vac Sci Technol, 1978, 15: 343-347

35 Tan BJ, Klabunde KJ, Sherwood PMA. XPS studies of solvated metal atom dispersed catalysts. Evidence for layered cobalt-manganese particles on alumina and silica. J Am Chem Soc, 1991, 113: 855-861

36 Sun Y, Xia Y. Alloying and dealloying processes involved in the preparation of metal nanoshells through a galvanic replacement reaction. Nano Lett, 2003, 3: 1569-1572

37 Chen HM, Liu RS, Lo MY, et al. Hollow platinum spheres with nanochannels: synthesis and enhanced catalysis for oxygen reduction. J Phys Chem C, 2008, 112: 7522-7526

38 Ye F, Liu H, Hu W, et al. Heterogeneous Au-Pt nanostructures with enhanced catalytic activity toward oxygen reduction. Dalton Trans, 2012, 41: 2898-2903

39 Liu Z, Lee JY, Han M, et al. Synthesis and characterization of PtRu/C catalysts from microemulsions and emulsions. J Mater Chem, 2002, 12: $2453-2458$

40 Zhang X, Chen KY. Water-in-oil microemulsion synthesis of platinum-ruthenium nanoparticles, their characterization and electrocatalytic properties. Chem Mater, 2003, 15: 451-459

41 Ye F, Liu H, Yang JH, et al. Morphology and structure controlled synthesis of ruthenium nanoparticles in oleylamine. Dalton Trans,
2013, 42: 12309-12316

42 Kishi K, Sasanuma M. The interaction of $\mathrm{O}_{2}$ with $\mathrm{Cu} / \mathrm{Ni}(100)$ and $\mathrm{Cu} / \mathrm{NiO} / \mathrm{Ni}(100)$ surfaces studied by XPS. J Electron Spectrosc Relat Phenom, 1989, 48: 421-434

43 Kim BC, Wallace GG, Yoon YI, et al. Capacitive properties of $\mathrm{RuO}_{2}$ and Ru-Co mixed oxide deposited on single-walled carbon nanotubes for high-performance supercapacitors. Synthetic Mat, 2009, 159: 1389-1392

44 Pusawale SN, Deshmukh PR, Gunjakar JL, et al. $\mathrm{SnO}_{2}-\mathrm{RuO}_{2} \mathrm{com}$ posite films by chemical deposition for supercapacitor application. Mater Chem Phys, 2013, 139: 416-422

Acknowledgments This work was supported by the National Natural Science Foundation of China (21173226, 21376247, 21573240 and 21506225), Center for Mesoscience, Institute of Process Engineering, Chinese Academy of Sciences (COM2015A001), and the Knowledge Innovation Program of the Chinese Academy of Sciences (KGCX2-YW-341).

Author contributions Tan Q, Wang P, Liu H and Xu Y performed the materials synthesis, characterization and electrochemical measurements. Chen $\mathrm{Y}$ was involved in data analysis and discussion. Yang J conceived the strategy, supervised the design of experiments, and wrote the manuscript, and all authors participated in the review of the manuscript.

Conflict of interest The authors declare that they have no conflict of interest.

Supplementary information Experimental details are available in the online version of the paper. 

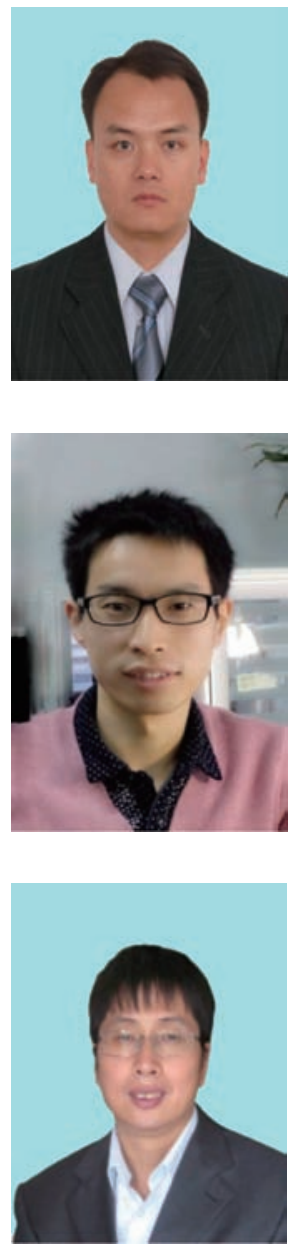

Qiangqiang Tan received his $\mathrm{PhD}$ degree in physical chemistry of metallurgy at the University of Science and Technology Beijing in 2003. After two years of postdoctoral research at the Institute of Electrical Engineering, Chinese Academy of Sciences (IPE-CAS), he joined the State Key Laboratory of Multi-phase Complex System, IPE-CAS, as an associate professor, and was then promoted to be a full professor. His research interest focuses on novel materials for energy conversion and storage, novel ceramics materials, and comprehensive utilization of ore resources.

Pengfei Wang received his BSc degree in chemical engineering and processing at Harbin Engineering University in 2012. $\mathrm{He}$ is currently a $\mathrm{PhD}$ student at the Institute of Process Engineering, Chinese Academy of Sciences (IPE-CAS). His research focuses on the metal oxide-based nanocomposites as highly efficient electrode materials for supercapacitors.

Jun Yang received his PhD degree in chemical and biomolecular engineering in 2006 from National University of Singapore. After postdoctoral research at Boston College and University of Toronto, he joined the Institute of Bioengineering and Nanotechnology, Singapore in 2007. In 2010, he moved to the Institute of Process Engineering, Chinese Academy of Sciences as the group leader of Materials for Energy Conversion and Environmental Remediation (MECER). His main research interests include applied catalysis, nanocomposites for energy conversion, synthesis and application of novel nanocrystalline materials, and separation techniques.

\section{中空 $\mathrm{MO}_{x}-\mathrm{RuO}_{2}$ 纳米结构用作高效超级电容器电极材料}

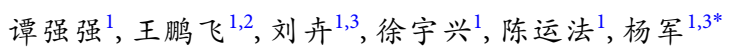

摘要 以低成本的方式调控纳米材料的内部结构和化学成分对增强其在特定应用中的性能非常重要, 但挑战巨大. 本文将电置换反应与一 种热处理过程相结合, 报道了一种具有普适性的途径制备钉基二元和三元氧化物纳米中空结构, 并测定了其作为超级电容器电极材料的 性能. 结果表明, 采用 $\mathrm{KOH}$ 为电解质, 在 $\mathrm{RuO}_{2}$ 的质量分数仅为 $19.6 \%$ 时, 所获得的负载于碳纳米管表面的中空 $\mathrm{NiO}^{-} \mathrm{RuO}_{2}$ 纳米结构在恒电流 密度为 $1 \mathrm{~A} \mathrm{~g}^{-1}$ 时具有 $740 \mathrm{~F} \mathrm{~g}^{-1}$ 的比容量, 并且具有良好的循环稳定性. 在恒电流密度为 $5 \mathrm{~A} \mathrm{~g}^{-1}$ 时, 比容量仍可以保持在 $638.4 \mathrm{~F} \mathrm{~g}^{-1}$. 本文以 $\mathrm{RuO}_{2}$ 提高过渡金属的导电性, 以过渡金属降低 $\mathrm{RuO}_{2}$ 材料成本并结合中空结构增加材料表面积的思路, 可以借鉴用来制备其它金属氧化物 体系以满足特定应用的需求. 